\title{
THE LATEST STREAMS OF RESEARCH ON COMMUNICATION IN RISK MANAGEMENT: A LARGE-SCALE LITERATURE REVIEW BASED ON CO-OCCURRENCE DATA
}

\author{
Iwona GORZEŃ-MITKA \\ Czestochowa University of Technology, Faculty of Management; iwona.gorzen-mitka@wz.pcz.pl, \\ ORCID: 0000-0002-2844-0054
}

Purpose: The scientific research on risk management has grown substantially over the past years. Communication on risk is central to the risk management strategy. As indicated by many researchers, communication is one of the key components of a successful risk management framework but, on the other hand, it is one of main categories of disruption and inefficiency in risk management process.

Design/methodology/approach: The research aim is identification of the latest streams of research that concern communication in risk management by knowledge mapping and it provides a visualization reference in this research field. Some series of published papers on communication aspects in risk management in Scopus database from 2000 to 2018 were extracted. Then, based on the co-occurrence frequencies of key terms, mapping is done and clustering keywords are extracted by using VOSviewer software.

Findings: The main research conclusions are as follows: (1) that communication studies are developing rapidly in the global academic community, (2) the frontier topics in this study consist of seven representative areas concentrated in main keywords like risk assessment, project management, risk perception, decision making, information management, risk analysis, disasters, and information technology, (3) the latest trends in research on communication aspects in risk management mainly include leadership context, climate change (especially regarding floods), food safety, corporate social responsibility, social media, and construction project.

Research limitations/implications: This study investigated only leading trends in this area and identified selected challenges in an exploratory way.

Practical implications: (not applicable).

Social implications: (not applicable).

Originality/value: This paper delivers an outline for main research trends in risk communication process within organisation.

Keywords: risk management, communication, co-occurrence analysis, large-scale literature review.

Category of the paper: Research paper. 


\section{Introduction}

The literature on communication is relatively large. Communication is an inherent part of all decision-making processes in an organization (Beretta and Bozzolan, 2004; Bussotti, 2017; Gorzeń-Mitka, 2016; Janoske, Brooke and Sheppard, 2012). Because decision-making in today's complex environment requires operating effectively under conditions of uncertainty and rapid change (Palenchar and Heath, 2007; Wieczorek-Kosmala, 2017). Strategic decisionmaking in complex environments requires teaching meta-cognitive skills that provide leaders with a tool-bag of decision-options to use when confronting novel situations (Jelonek et al., 2020; Sipa, 2018; Skibiński, 2018; Sitek, 2018). This also requires the development of innovative and adaptable decision models, also in communication processes, beyond the linear thinking underlying the rational actor model that has characterized traditional strategic decision-making (Hopkin, 2014; Gorzeń-Mitka, 2015a; 2019). In the strategy literature, communication is mainly viewed as a primarily tactical function, but nowadays researchers increasingly indicate the strategic context of communication (Palenchar and Heath, 2007; Danisman and Demirel, 2019; Kelay and Fife-Schaw, 2010). Especially in a risk management context, it is a very important issue (Bochet, Laurent-Lucchetti, Leroux, and Sinclair-Desgagné, 2019; Hopkin, 2014; Gorzeń-Mitka, 2015b).

Among the many approaches to risk management, communication aspects are particularly emphasized in enterprise risk management approach (Bochet, Laurent-Lucchetti, Leroux, and Sinclair-Desgagné, 2019; Danisman and Demirel, 2019, Gorzeń-Mitka, 2016). Nowadays research in this area concludes that the process should be anchored in the main strategy of the organization as well as in the strategies of its individual units (Wieczorek-Kosmala, 2017; Gorzeń-Mitka, 2019, Kim and Vonortas, 2014). Enterprise risk management (ERM) is an important business trend aimed at ensuring an organized and disciplined approach of an organization to the evaluation and management of risks it encounters (Taarup-Esbensen, 2019; Hopkin, 2014; Wieczorek-Kosmala, 2017). Problems of communication in risk management are studied from the many varieties of research perspectives (e.g. social sciences, medicine, computer science) (McComas, 2006; Ng and Hamby, 1997; Smolarek and Sipa, 2017). In recent years, we can observe very intensive development in this area. Nowadays, some researchers suggest that risk management, especially in ERM context, is the key factor to create competitive advantages (Kraus and Lehner, 2012; Gorzeń-Mitka, 2016; Danisman et al., 2019).

Communication is a crucial element shaping the effective risk management system. As indicated by most risk communication experts, understandable information is inadequate. The communication is also strongly correlated to the performance. Nowadays there is a significantly increasing pressure on the speed of communication, transparency, relevance, and volume of data transmitted. As stressed by Beretta and Bozzolan (2004), Janoske et al. (2012), 
Gorzeń-Mitka (2016), it is very important to understand that communication on risk takes place as a dialogue between different stakeholders with different interests and different ways of looking at things. An important part of this process is also the inclusion of risk perceptions aspects (social contexts, like for example feelings, instincts, risk attitude).

Communication on risk should be provided against the background of that existing risk perception. As indicated by many researchers, to manage risk effectively it is important to build strong communication flows and data reporting (Hopkin, 2014; Janoske et al., 2012; McComas, 2006). It is necessary for employees at all levels in the organization to have the information and to evaluate and act on risks and opportunities. Communication is needed to share recommendations on ways to improve performance while remaining within acceptable risk thresholds (Ng and Humby, 1997). In a company, better communication starts with clear risk responsibilities: who needs to know, what, and when they need to act.

Also, development of information communication technologies (ICT) over the past decade has affected the changing ways of communication in the organization, making them far more complex, challenging and, on the other hand, riskier (changing ways in information reception, its understanding and reaction process). For example, cyber risks are currently key challenges on the organization risk map.

As indicated by $\mathrm{Ng}$ and Hamby (1997) and McComas (2006), communication in risk management is a process of exchanging information among interested parties about the nature, magnitude, significance, or control of risk. It can be broadly understood as an iterative exchange of information among individuals, groups, and institutions related to the assessment, characterization, and management of risk. Other researches point to the importance of understanding the risk nature in communication processes. They indicate that a very important factor is the awareness that risk encompasses both objective and subjective qualities and that risk judgment is, to some degree, a by-product of social, cultural, and psychological influences. Current research in risk assessment and management indicates an understanding that judgments on risk are not limited to assessments of physical processes but are also reflections of the understanding of social systems and the actors playing roles within them (McComas, 2006; Keley and Fife-Schaw, 2010).

Mainstream literature also strongly emphasises that communication on risk is based on attempts to enhance stakeholders trust. In an analysis of the disclosure of risks made by companies, attention has to be paid not only to how much is disclosed but also to what is disclosed and how. Communication arrangements are an important part of the risk culture. Organizations with a strong risk-aware culture are characterized by communication founded on mutual trust and a shared perception of the importance of risk management (Hopkin, 2014).

The multidimensionality of variables that shape the effectiveness of the communication process in an organization causes that identification of knowledge in the types of research current trends in the context of communication in risk management is important for further development of this area. This study mainly focuses on identifying research threads undertaken 
in management within communication research in risk management context over past years. The main research question is: how has the perspective of academic research in communication changed (how has it evolved), especially in risk management concept, over the past twenty years, what are the leading research areas, and what are the new trends in this research. Scopus was the database which provided data for the analysis. The result of the research was presented in the form of a knowledge map (Xin et al., 2018, Ziegler, 2009). The main method used while preparing this article is an overview of the academic literature (especially in Scopus database) and network analysis.

\section{Methods and preliminary research}

The article presents the results of the large-scale literature review regarding a communication perspective in risk management that are based on keywords co-occurrence network analysis. The study consisted of the following stages (Figure 1).

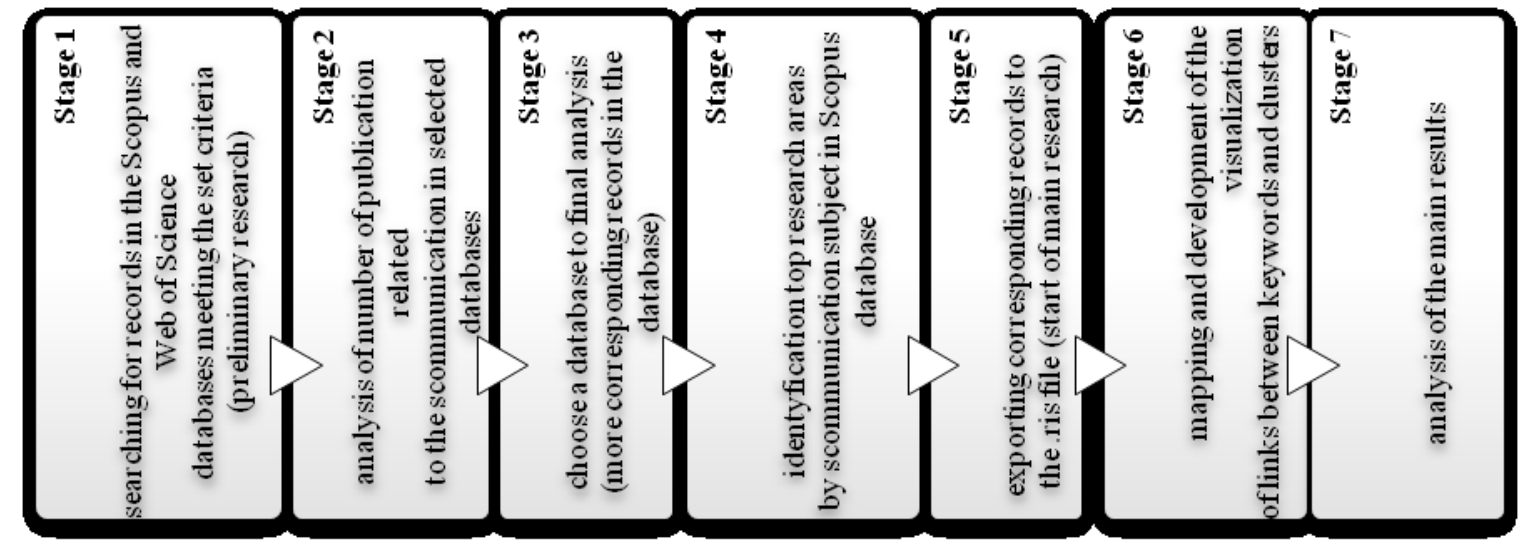

Figure 1. The large-scale literature review regarding a communication perspective in risk management - stages of research. Source: own elaboration.

In the first stage of the research the Author used two databases: the Web of Science and Scopus. Research activity on the communication concept was assessed by the number of publications. As indicated by Xin et al. (2018) the quantity variation of academic papers on a subject is a vital indicator of the development trend in that research area, and a reflection of change in the extent of the subject knowledge. By plotting the number of literature over time and conducting multivariate statistical analysis, one can understand the research level and future development trend in a certain field. The breakdown of the number of publications is presented in Figure 2. 


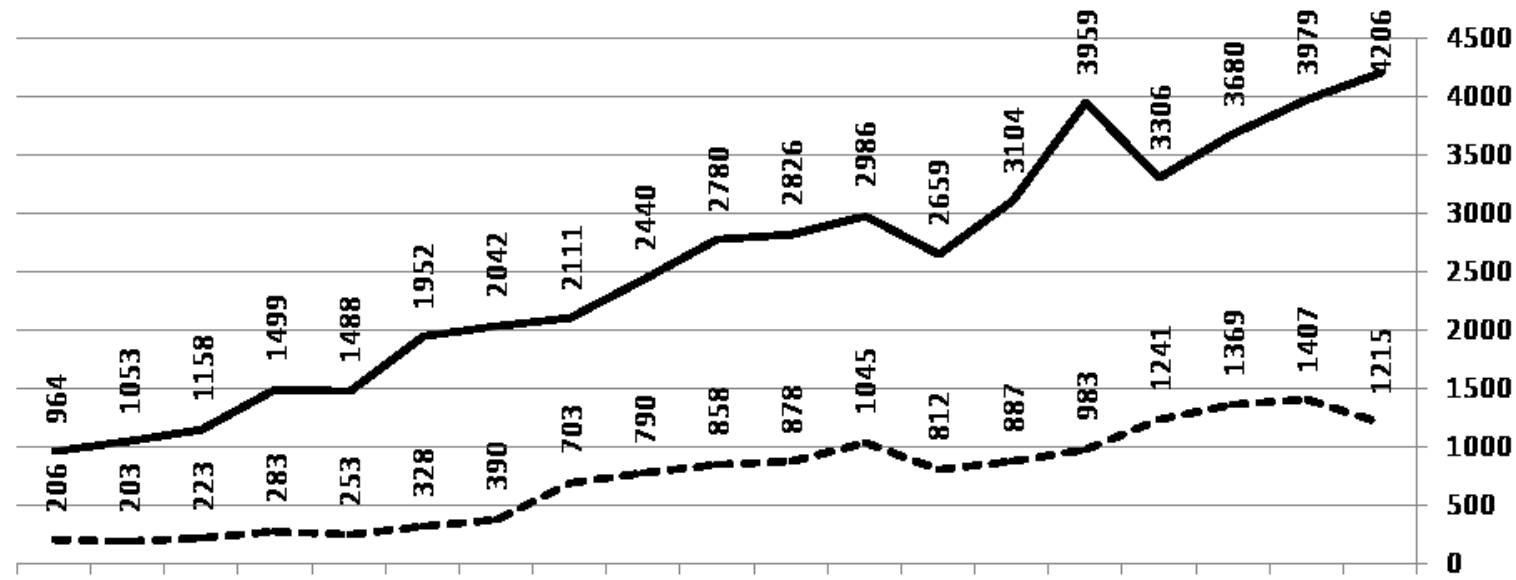

2000200120022003200420052006200720082009201020112012201320142015201620172018

Scopus -----Web of Science

Figure 2. Quantitative distribution of published articles in communication (topic "communication" in the Scopus and Web of Science databases in 1990-2018). Source: own processing, data extracted from Scopus and Web of Science databases.

Figure 2 shows that the number of publications related to the notion "communication" is similar in both databases, but generally more publications were collected in Scopus. The number of articles that included references to "communication" (keywords referred to the analysed area) was as follows:

- in Scopus database - 1,884,637 (general), 1,377,313 (in period after 2000) and 48,192 (in period after 2000 in management subject),

- in Web of Science database - 791,287 (general), 665,096 (in period after 2000) and 14,074 (in period after 2000 in management subject).

The set of generated data contained articles, conference papers, books and book chapters. The earliest research article on communication retrieved from the Web of Science was published in 1920, from Scopus - in 1861. While analysing the number of publications indexed in the Scopus database, considerable growth in the communication subject could be observed. Moreover, it should be noted that in the last two decades the number of publications regularly exceeded 100 papers per year. It can be seen from Figure 2 that during the entire period under consideration, more articles concerning communication were indexed in the Scopus database. Therefore, this database was selected for further analysis.

In the next stage the research identified the main areas of research related to communication topic in risk management. The analysis was concluded in relation to the criterion which involved a number of publications in top subject areas (Figure 3). 


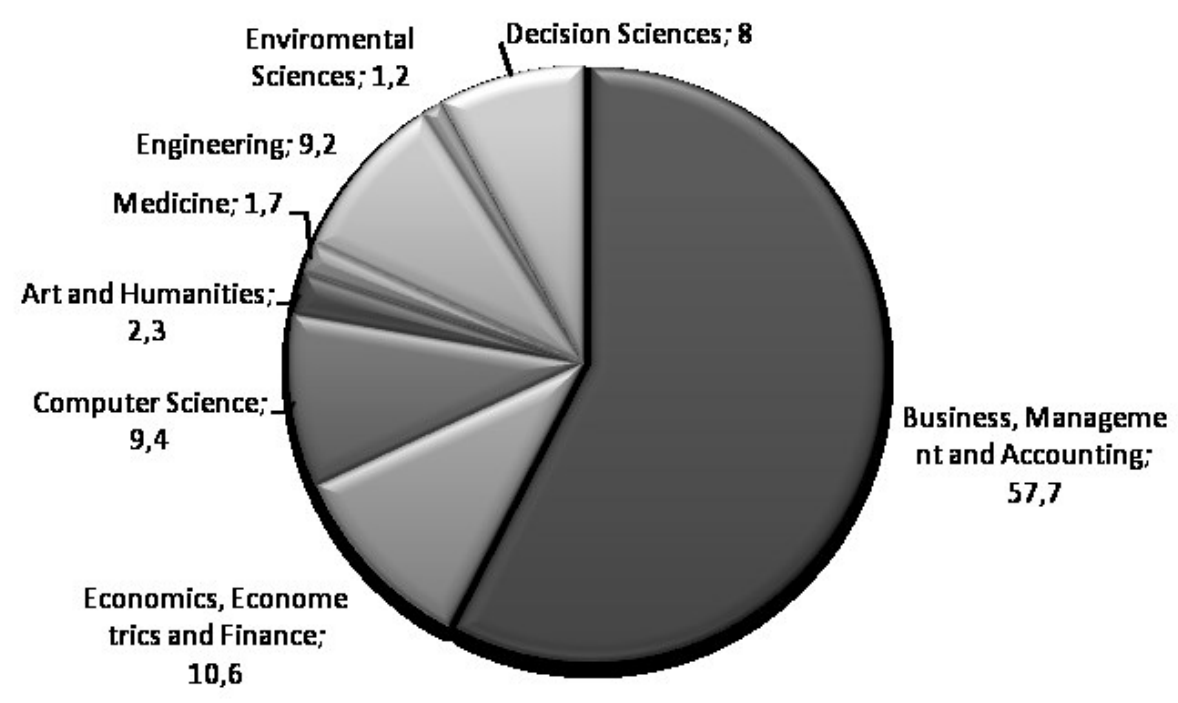

Figure 3. Top research areas by communication in management subject (\%). Source: own processing, data extracted from Scopus database.

It can be seen from Fig. 3 (4th stage of the research) that nature of communication studies in management by subject area has been quite concentrated. Researchers are coming mostly from domains such as Business, Management and Accounting (57.7\%), Economics, Econometrics and Finance (10.6\%) and Computer Science (9.4\%).

\section{Results and discussion}

Keywords co-occurrence analysis is used to analyse the link strength between co-occurrence keywords by studying their co-occurrence relation in a large number of documents (in this case finally 1,568 research papers from Scopus database). Its main purpose is to describe the internal relationship and structure as well as to reveal the research fronts of certain academic disciplines. Research front refers to inter alia basic research problems, as well as the rising or unexpectedly emerging theoretical trends and new topics. Results of keywords co-occurrence analysis of communication in risk management by VOSviewer software is shown in Fig. 4. Data selection and research procedure using the application VOSviewer was adapted from study by van Eck and Waltman (2019), Gudanowska (2017) and Xin et al. (2018). The analysis of the co-occurrence of keywords was performed with the use of the VOSviewer software (van Eck and Waltman, 2019; Xin et al., 2018). The analysis was based on the key-words included by the authors of the publications. As indicated by Xin et al. (2018) the keywords in academic publications are the natural language words that express the thematic concepts of documents. The keywords condense authors' academic viewpoints, becoming an important indicator in bibliometrics. Keywords co-occurrence analysis is based on the 
statistics of the number of pairs of keywords being cited in the same document, so as to conduct the network analysis and cluster analysis for these words and thus reveal the knowledge structure and research frontier of a certain subject. To present a clear visualisation, this paper focuses on those expressions that appeared at least 10 times in a group of selected publications.
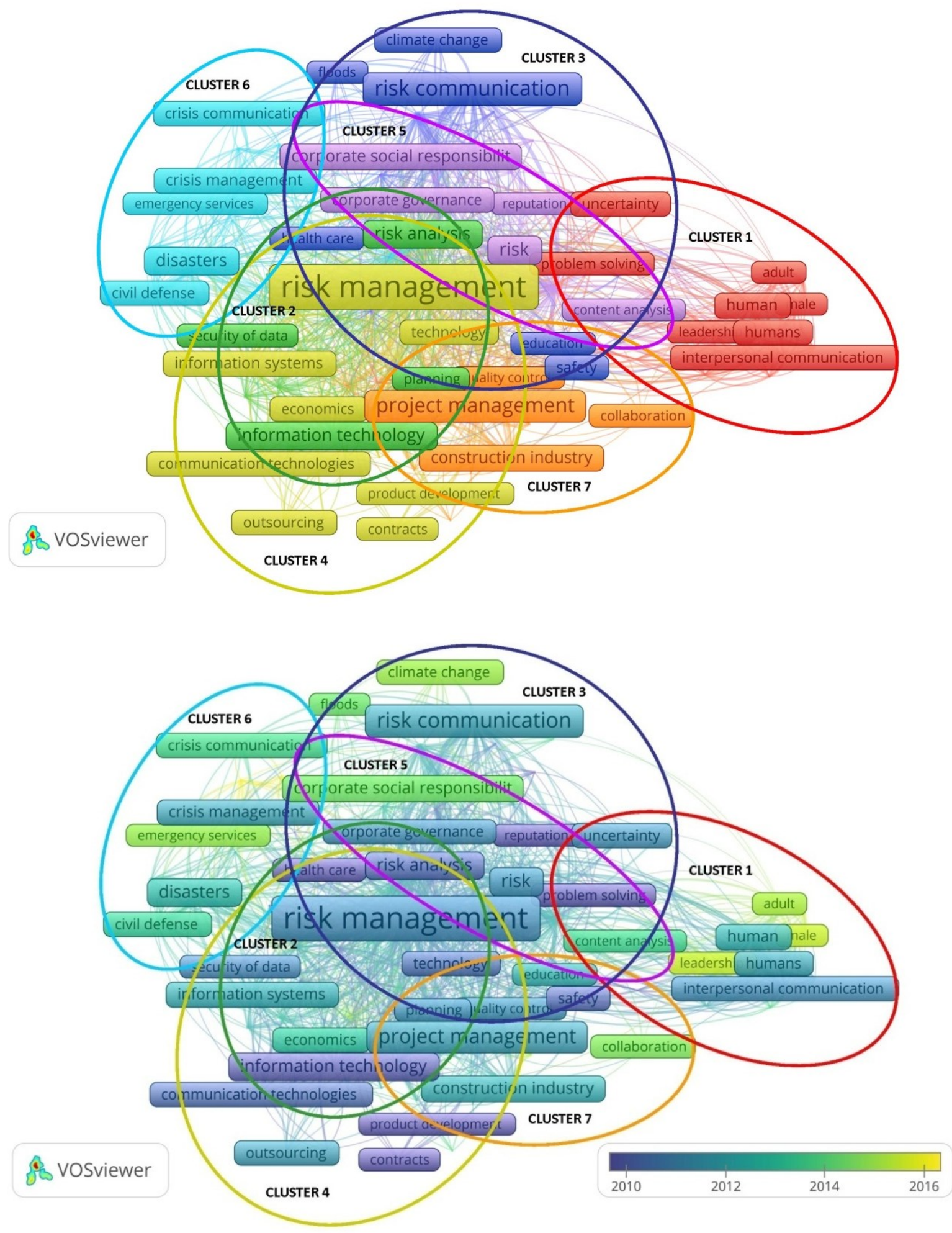

Figure 4. Keywords co-occurrence network and links detected in time in communication studies in risk management area. Source: own processing via VOSviewer software, data extracted from Scopus database. 
In Figure 4 it can be seen that the frontier topics of communication studies form seven clusters, and the keywords in the same cluster show greater similarity in respect of research topic. The map includes the most frequently occurring keywords. The size of the nodes representing each of the appearing keyword as well as the font size, in which the name of a given node is written, correspond to the frequency of the occurrence of a given term. The distance between items in the visualization approximately indicates the relatedness of them in the co-occurrence network. In general, the closer two items are located to each other, the stronger their relatedness in terms of occurrence links in an analysed group of publications (van Eck and Waltman, 2019). Figures 4-11 present the resulting maps: a whole map of co-occurrence keywords (Fig. 4) and maps of individual clusters and their links detected in time (Fig. 5-11).

Additionally, the resulting connection network is quite concentrated and it is characterized by numerous connections in the map and in each cluster. Keywords with the highest occurrence ratio (more then 50) and total link strength are the following: risk management (392), communication (162), risk assessment (146), risk communication (125), project management (119), risk perception (95), decision making (89), risk (65), information management (63), risk analysis (61), disasters (54) and information technology (51). Details on the main keywords and their characteristics by co-occurrences and total links strength related to this map are presented in Table 1 in the Appendix.

In the further part of the article comments on information from individual clusters were presented.

Cluster 1 (red): (keywords of coexistence include: human, interpersonal communication, uncertainty and uncertainty analysis, costs, problem solving, organization and management, organizational culture).

The first cluster classified in VOSviewer (Cluster 1, Fig. 5) was a group of issues related to, among others, human aspects in management. The most frequent and the most interrelated component in the cluster was the human and interpersonal communication. The importance of human aspects in the communication processes in the organization is indisputable. In the map of trends, the human aspects are clearly shifting into the direction towards the centre of the map in the cluster, which points to its numerous and quite strong connections with a large number of other issues. These elements exhibited a very strong relation with leadership and organizational culture. The communication aspects in leadership and gender context are a relatively new element in the cluster (see the figure on the right where links detected in time are presented). This may indicate that research on these issues are at a rather initial stage and are presented mainly through qualitative research (the link between elements is quite loose). It can be said that research in these areas is a new trend. 

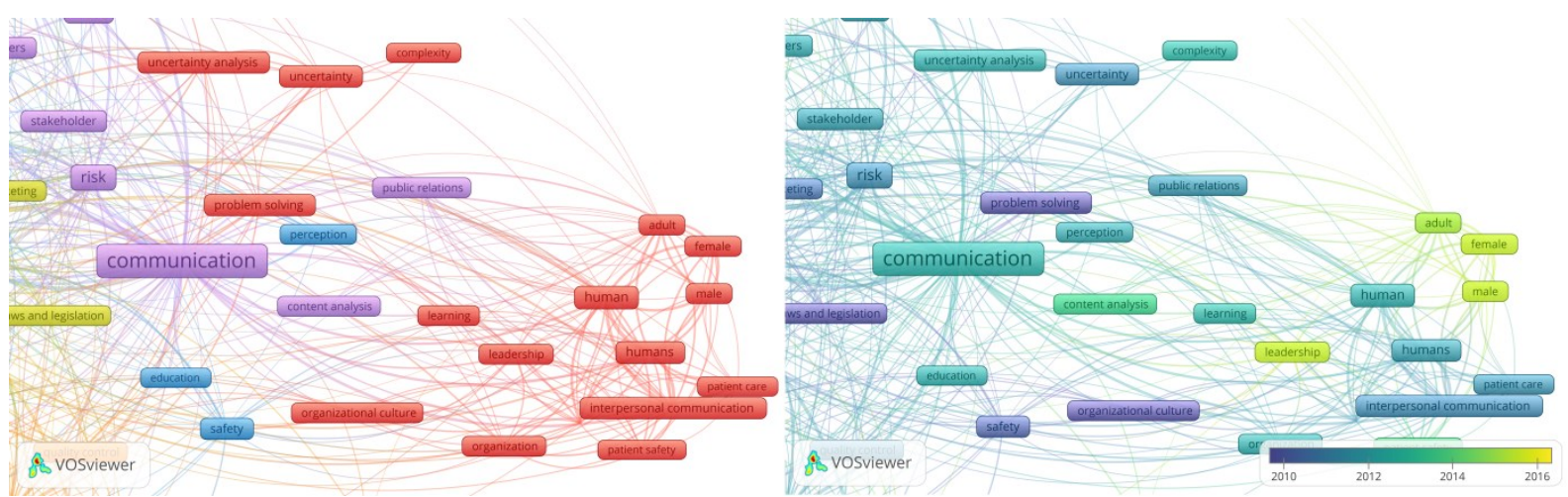

Figure 5. Keywords co-occurrence (left figure) and links detected in time (right figure) in communication studies in risk management area - cluster 1. Source: own processing via VOSviewer software, data extracted from Scopus database.

Cluster 2 (green): (keywords of coexistence include: risk assessment, risk analysis, information and communication technologies, supply chain management).

The second cluster classified in VOSviewer (Cluster 2, Fig. 6) was a group of issues related to, among others, risk assessment and risk analysis problems in the context of information and communication technologies. Additionally, a significant part of the research grouped in this cluster refers to the issues of supply chain management.

As we can see in the right part of Figure 6, most of the distinguished issues have been analysed for over a decade. This may indicate that research on these issues is not the newest trend but it is still quite intensively developed (the link between elements is quite strong).

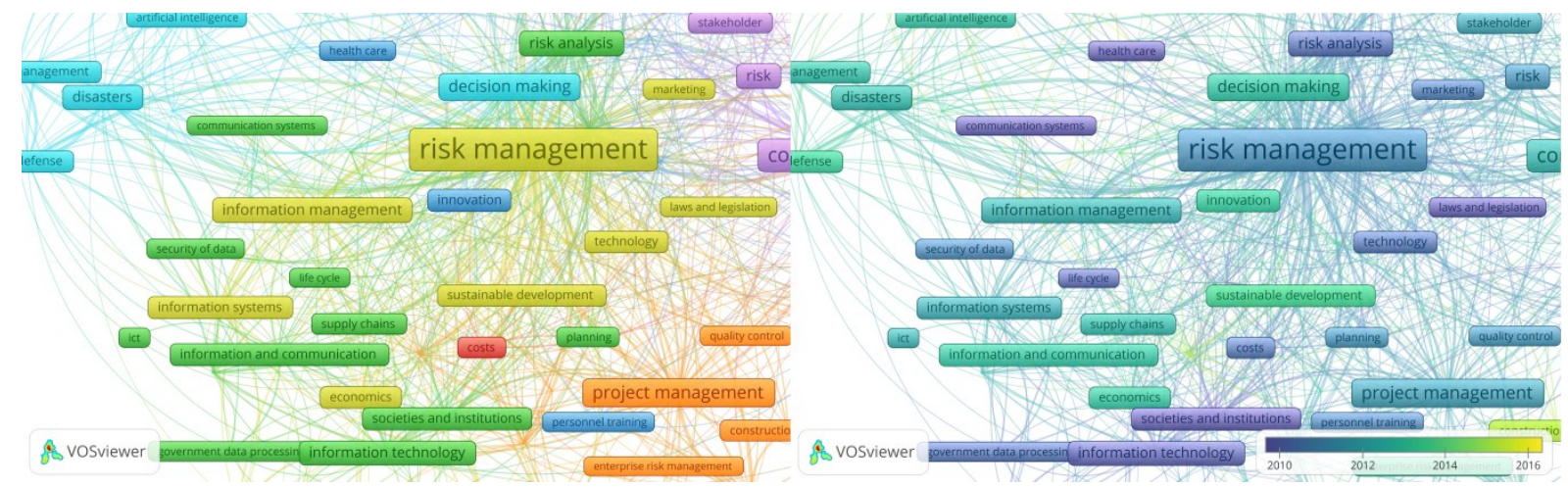

Figure 6. Keywords co-occurrence (left figure) and links detected in time (right figure) in communication studies in risk management area - cluster 2. Source: own processing via VOSviewer software, data extracted from Scopus database.

Cluster 3 (dark blue): (keywords of coexistence include: risk communication, risk perception, health risks, innovation, accident prevention, safety).

The third cluster is connected generally to the risk communication aspects. We can find there terms related to the risk perception and accident prevention in connection with innovation and safety perspective. We observe a strong development and specialization of different areas of communication within health, climate change, occupational risks and food context. It may indicate that these research from the perspective of communication are at a quite stable stage (but the link between elements is quite strong). It can be said that research in these areas presents a grounded, stable trend. 
However, it should be emphasized that the communication aspects in climate change (especially regarding floods) and food safety are relatively new elements in the cluster (see the figure on the right where links detected in time are presented). This may indicate that research on these issues is at a rather initial stage (the link between elements is quite loose). It can be said that research in these areas is a new trend.

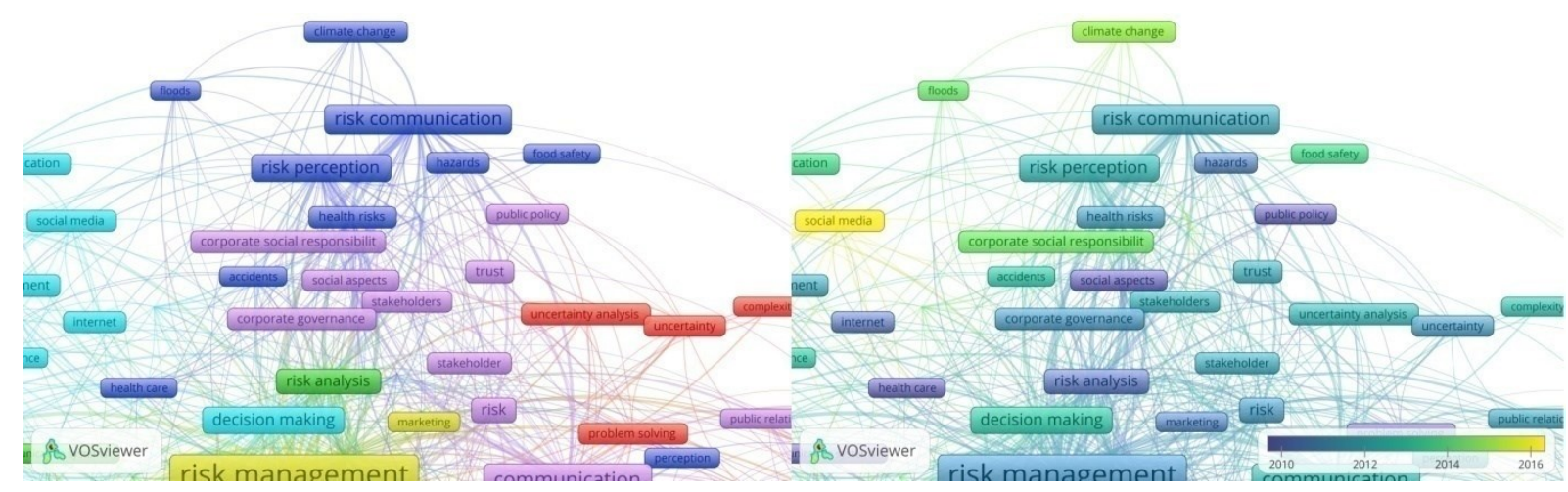

Figure 7. Keywords co-occurrence (left figure) and links detected in time (right figure) in communication studies in risk management area - cluster 3. Source: own processing via VOSviewer software, data extracted from Scopus database.

Cluster 4 (yellow): (keywords of coexistence include: risk management, information management, information systems, sustainable development, economics, industrial management).

The fourth classified cluster was a group of issues associated, among other things, with risk management in the information systems (especially communication technologies) context. These elements exhibited a very strong relation with sustainable development in law and legislation processes context. Risk management is clearly shifted into the direction towards the centre of the whole map of keywords co-occurrence.

As we can see in the right part of Figure 8 , most of the distinguished issues have been analysed for over a decade. This may indicate that research on these issues is not the newest trend but it is still quite intensively developed (the link between elements is quite strong).

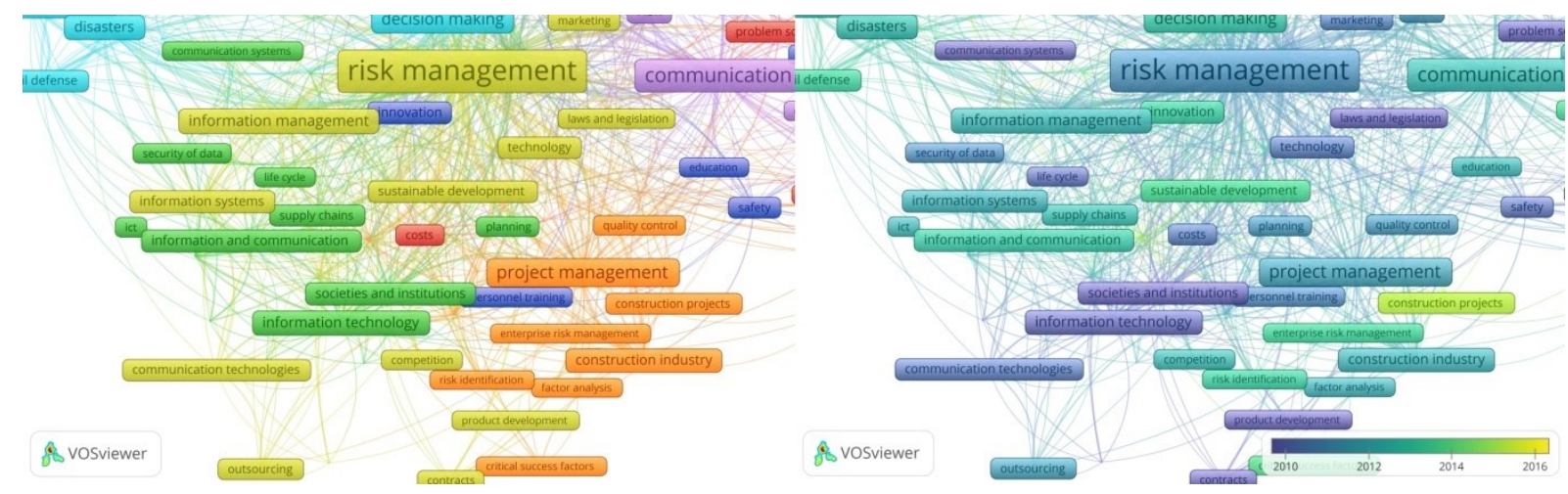

Figure 8. Keywords co-occurrence (left figure) and links detected in time (right figure) in communication studies in risk management area - cluster 4. Source: own processing via VOSviewer software, data extracted from Scopus database. 
Cluster 5 (violet): (keywords of coexistence include: communication, risk, trust, social aspects, public relations, stakeholder, stakeholders, public policy).

The fifth classified cluster was a group of issues associated, among other things, with the communication issues in the public sector and social aspects. These elements exhibited a quite strong relationship with corporate social responsibility context. Communication as the main keyword in this cluster is clearly shifted to the centre of the whole map of keywords cooccurrence, which points to its strong connections with other issues.

Additionally, as we can see in the right part of Figure 9, aggregation of communication research from a corporate social responsibility perspective is at a rather initial stage. It can be said that the research in these areas is a new trend.

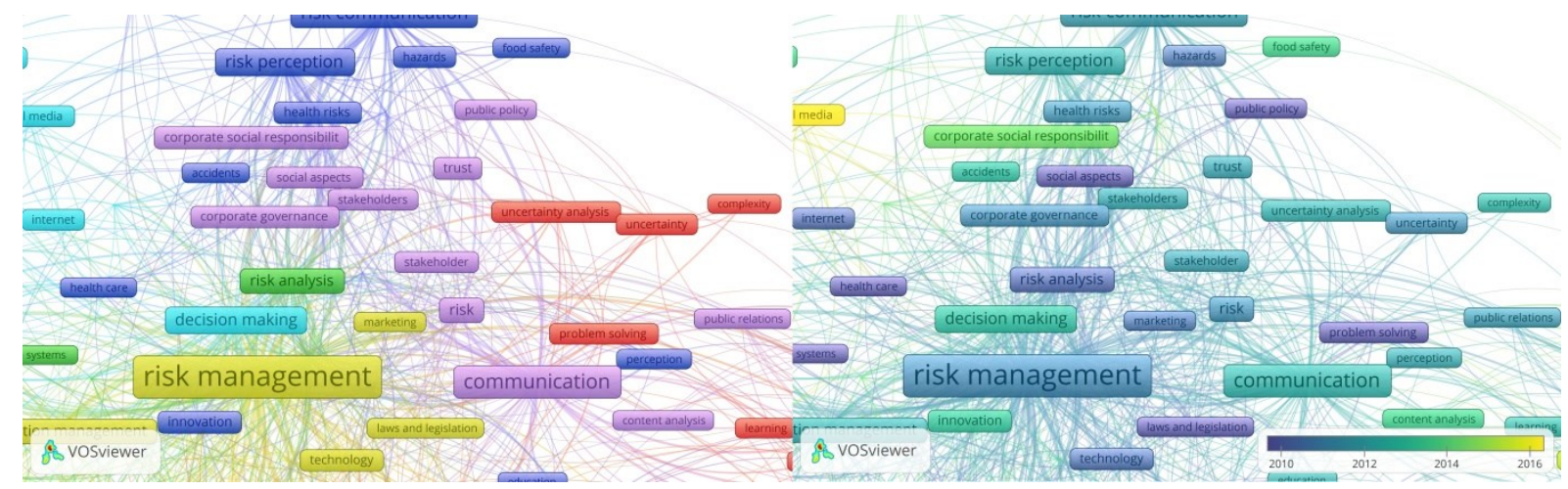

Figure 9. Keywords co-occurrence (left figure) and links detected in time (right figure) in communication studies in risk management area - cluster 5. Source: own processing via VOSviewer software, data extracted from Scopus database.

Cluster 6 (aqua blue): (keywords of coexistence include: decision making, disasters, civil defence, emergency management, crisis management, social networking (online)).

The sixth classified cluster was a group of issues associated, among other things, with the communication issues in the decision making processes in disasters, civil defence and emergency and crisis management. These elements exhibited a quite strong relationship with social networking context. Decision making as the main keyword in this cluster is clearly shifted to the centre of the whole map of keywords co-occurrence, which points to its strong connections with other issues.

Additionally, as we can see in the right part of Figure 10, aggregation of communication research from a social media perspective is at a rather initial stage. It can be said that the research in these areas is a new trend. 

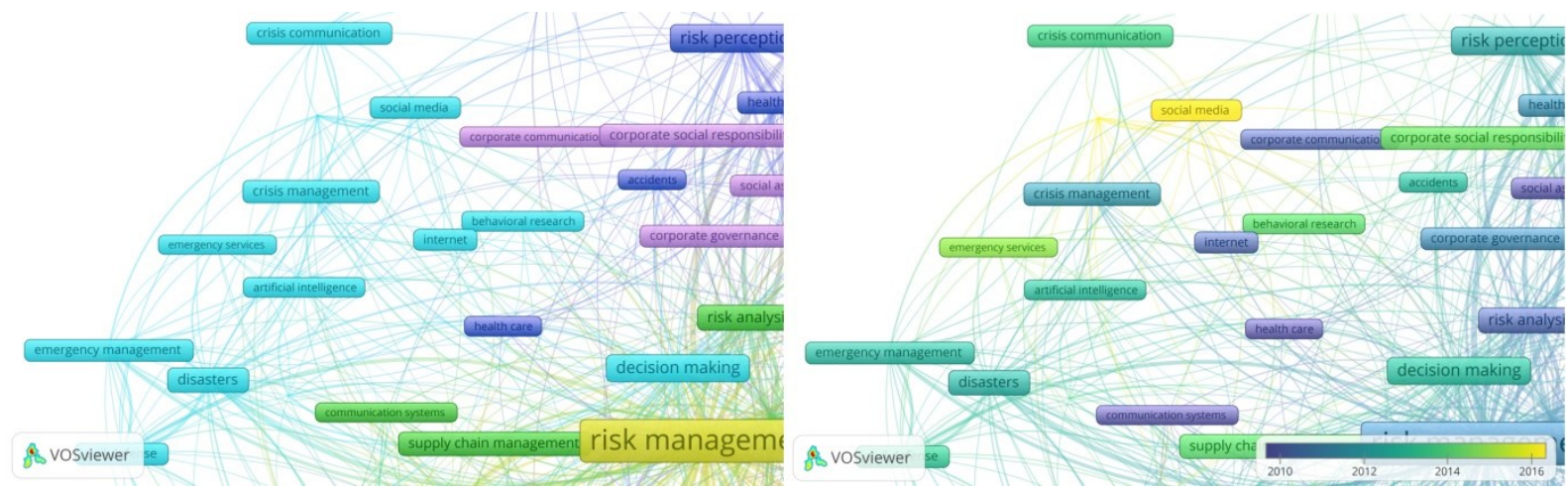

Figure 10. Keywords co-occurrence (left figure) and links detected in time (right figure) in communication studies in risk management area - cluster 6 (aqua blue). Source: own processing via VOSviewer software, data extracted from Scopus database.

Cluster 7 (orange): (keywords of coexistence include: project management, construction industry, knowledge management, human resources management, construction projects).

The last classified cluster was a group of issues associated, among other things, with the communication issues in the project management (especially in the construction sector). These elements exhibited a quite strong relationship with knowledge management (especially in knowledge-based systems) and human resources management context. Project management as the main keyword in this cluster is clearly shifted away from the centre of the whole map of keywords co-occurrence, which points to its looser connections with other issues. Additionally, as we can see in the right part of Figure 11, aggregation of communication research from a construction project perspective is at a rather initial stage. It can be said that the research in these areas is a new trend.

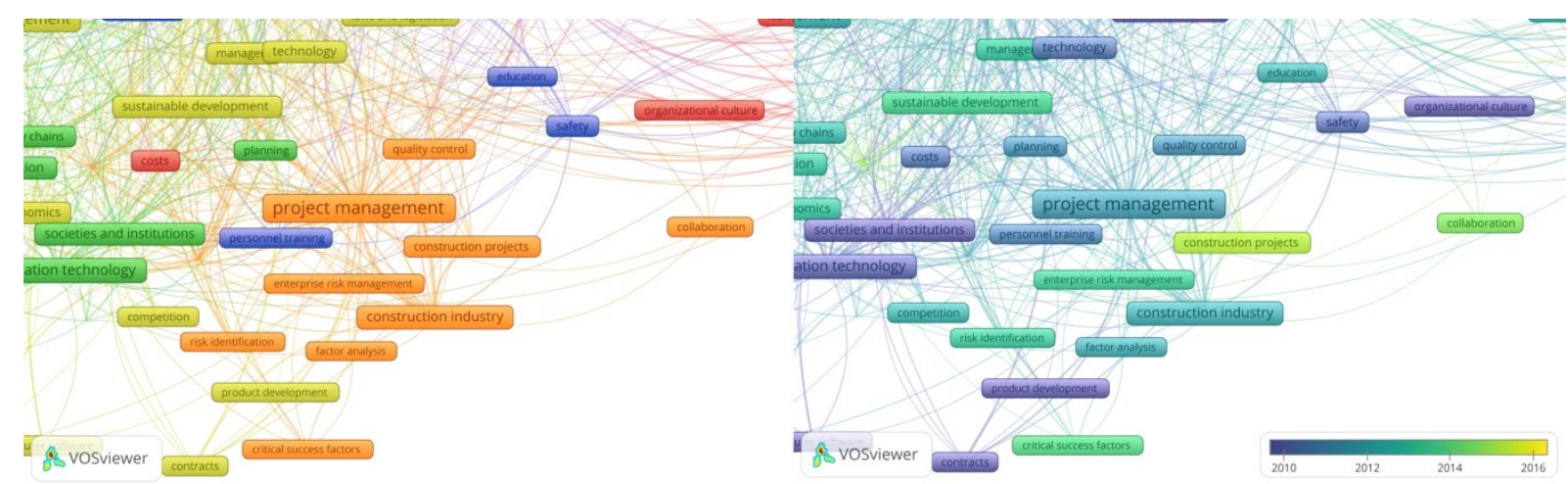

Figure 11. Keywords co-occurrence (left figure) and links detected in time (right figure) in communication studies in risk management area - cluster 7 (orange) Source: own processing via VOSviewer software, data extracted from Scopus database. 


\section{Limitation of this study and future research}

Research on communication is undoubtedly a multidimensional concept (not only in management science), and in this study we investigated only the leading trends in this area. There are many other areas of challenges in communication in risk management and future research should investigate the relationships between other dimensions of this concept. Secondly, this research aimed to identify selected challenges in an exploratory way. Also, because of the qualitative nature of the research, the results do not have universal validity. Future research could extend the research concept here identified, complementing it with dedicated areas, such as business aspects. Finally, based on this study, future research could use these findings in management practice. Additionally, research on communication in risk management context can be extended by e.g. document co-citation analysis.

\section{Summary}

A large-scale literature review based on co-occurrence network analysis by the VOSviewer software was used for analysis and new trends identification in communication studies from a risk management perspective. The main research conclusions are as follows:

- The vigorous growth of the number of articles indicates that communication studies are developing rapidly in the global academic community.

- By clustering network map for keywords co-occurrence and analysing the research activities in communication studies in risk management area, it was found that the frontier topics in these studies consist of seven representative areas concentrated in main keywords such as risk management, communication, risk assessment, risk communication, project management, risk perception, decision making, risk, information management, risk analysis, disasters, and information technology.

- The latest trends in research on communication aspects in risk management have been identified as follows: communication aspects in leadership and gender context, communication aspects in climate change (especially regarding floods) and food safety, communication aspects in a corporate social responsibility perspective, communication aspects in social media perspective and communication aspects in construction project perspective.

Same communication aspects in risk management undoubtedly still constitute great challenges to academic researchers and managers. The complexity and multidimensionality of the variables that determine communication processes require the decision-makers to take 
a look at the role of risk management in company processes from different perspectives (i.e. "soft" behaviours).

In the author's opinion, the results of the research presented in this study may provide a basis for further work in this area.

By summarizing the above indicated trends in contemporary research on communication in the context of risk management, one may say that this area undoubtedly constitutes great challenges to modern entities.

\section{Acknowledgements}

The research project founded by the Częstochowa University of Technology, Faculty of Management, Poland.

\section{References}

1. Beretta, S., and Bozzolan, S. (2004). A framework for the analysis of firm risk communication, International Journal of Accounting, Vol. 39, Iss. 3, pp. 265-288. doi:10.1016/j.intacc.2004.06.006.

2. Bochet, O., Laurent-Lucchetti, J., Leroux, J., and Sinclair-Desgagné, B. (2019). Collective risk-taking in the commons. Journal of Economic Behavior and Organization, Vol. 163, pp. 277-296. doi:10.1016/j.jebo.2019.04.011.

3. Bussotti, L. (2017). Risk management and risk communication in Mozambique: the case of arms and ammunition depots of Malhazine. Problems of Management in the 21st Century, Vol. 12, Iss. 2, pp. 94-105.

4. Danisman, G.O., and Demirel, P. (2019). Corporate risk management practices and firm value in an emerging market: A mixed methods approach. Risk Management, Vol. 21, Iss. 1, pp.19-47. doi: 10.1057/s41283-018-0040-5.

5. Gorzeń-Mitka, I. (2015). Gender differences in risk management. Small and medium sized enterprise perspective. Research Papers of the Wroclaw University of Economics/Prace Naukowe Uniwersytetu Ekonomicznego we Wroclawiu, Vol. 412, pp. 80-89.

6. Gorzeń-Mitka, I. (2015). Management challenges in the context of risk culture. Problems of Management in the 21st Century, Vol. 10, Iss. 2, pp. 60-61.

7. Gorzeń-Mitka, I. (2016). Leading Risk Management Determinants of Small and MediumSized Enterprises (SMEs): An Exploratory Study in Poland. Eurasian Studies in Business and Economics, Vol. 3, Iss. 1, pp. 289-298. doi: 10.1007/978-3-319-27570-3_23. 
8. Gorzeń-Mitka, I. (2019). Interpretive structural modeling approach to analyze the interaction among key factors of risk management process in SMEs: Polish experience. European Journal of Sustainable Development, Vol. 8, Iss. 1, pp. 339-349. doi: 10.14207/ejsd.2019.v8n1p339.

9. Gudanowska, A.E. (2017). A map of current research trends within technology management in the light of selected literature. Management and Production Engineering Review, Vol. 8, Iss. 1, pp.78-88. doi: 10.1515/mper-2017-0009.

10. Hopkin, P. (2014). Fundamentals of risk management: understanding, evaluating and implementing effective risk management. London, England, Philadelphia, Pennsylvania, New Delhi, India: Kogan Page.

11. Janoske, M., Brooke L., and Sheppard, B. (2012). Understanding Risk Communication Best Practices: A Guide for Emergency Managers and Communicators, Report to Human Factors/Behavioral Sciences Division, Science and Technology Directorate, U.S. Department of Homeland Security. College Park, MD: START.

12. Jelonek, D., Mesjasz-Lech, A., Stępniak, C., Turek, T., and Ziora, L. (2020). The artificial intelligence application in the management of contemporary organization: Theoretical assumptions, current practices and research review. Lecture Notes in Networks and Systems. Vol. 69, pp. 319-327. doi: 10.1007/978-3-030-12388-8_23.

13. Kelay, T., and Fife-Schaw, Ch. (2010). Effective Risk Communication: A Guide to Best Practice. Retrieved from https://www.techneau.org/fileadmin/files/Publications/ Publications/Deliverables/D6.3.1-2.report.pdf, 7.06.2019.

14. Kim, Y., and Vonortas, N.S. (2014). Managing risk in the formative years: Evidence from young enterprises in Europe. Technovation, Vol. 34, Iss. 8, pp. 454-465. doi: 10.1016/ j.technovation.2014.05.004.

15. McComas, K.A. (2006). Defining moments in risk communication research: 1996-2005. Journal of Health Communication, Vol. 11, Iss. 1, pp. 75-91. doi: 10.1080/ 10810730500461091.

16. Ng, K.L., and Hamby, D.M. (1997). Fundamentals for establishing a risk communication program. Health Physics, Vol. 73, Iss. 3, pp. 473-482.

17. Palenchar, M.J. and Heath, R.L. (2007). Strategic risk communication: Adding value to society. Public Relations Review, Vol. 33, Iss. 2, pp. 120-129. doi: 10.1016/ j.pubrev.2006.11.014.

18. Sipa, M. (2018). The Factors Determining the Creativity of the Human Capital in the Conditions of Sustainable Development, European Journal of Sustainable Development, Vol. 7, Iss. 2, pp. 1-13. doi: 10.14207/ejsd.2018.v7n2p1.

19. Sitek, M. (2018). Assessment Of Sustainable Development Of The Residential Construction Sector In The Context Of Sustainable City Development In Poland. European Journal of Sustainable Development, Vol. 7, Iss. 3, pp.434-444. doi: 10.14207/ejsd.2018.v7n3p434. 
20. Skibiński, A. (2018). Assessment of the Degree Aging Labour Force for Example of Poland and Slovakia. European Journal of Sustainable Development, Vol. 7, Iss. 3, pp. 473-482. doi: 10.14207/ejsd.2018.v7n3p473-482.

21. Smolarek, M., and Sipa, M. (2017). The impact of CSR on the competitive position of small and medium enterprises. In: A.Jabłoński (Ed.), Sustainability and Scalability of Business: Theory and Practice (pp. 267-278). New York: Nova Science Publishers.

22. Taarup-Esbensen, J. (2019). Making Sense of Risk-A Sociological Perspective on the Management of Risk. Risk Analysis, Vol. 39, Iss. 4, pp. 749-760. doi: 10.1111/risa.13211.

23. van Eck, N.J., Waltman, L. (2019). VOSviewer Manual. Manual for VOSviewer version 1.6.11, software documentation.

24. Wieczorek-Kosmala, M. (2017). Kapitat ryzyka w przedsiębiorstwie. Warszawa: CEDEWU.

25. Xin, Z., Wen Long, Y., and Hai, L.V. (2018). Visualization and analysis of mapping knowledge domain of road safety studies. Accident Analysis and Prevention, Vol. 118, pp. 131-145. doi: 10.1016/j.aap.2018.06.010. 


\section{Appendix}

Table 1.

Communication in risk management - analysis results by selected clusters

\begin{tabular}{|c|c|c|c|c|c|c|c|c|}
\hline 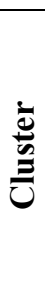 & 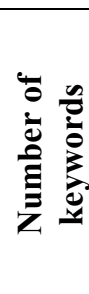 & 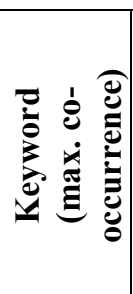 & 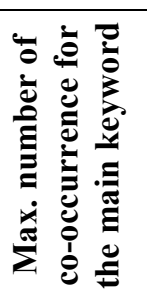 & 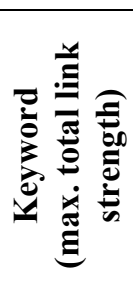 & 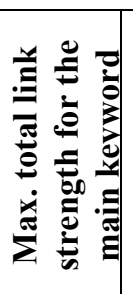 & 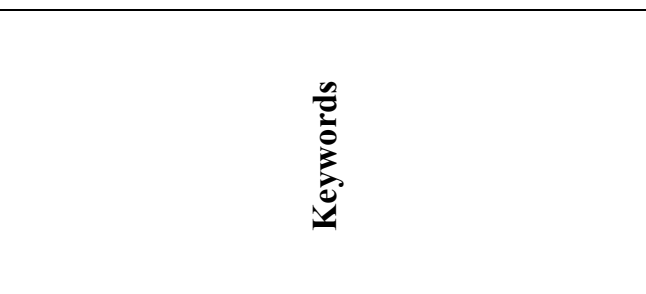 & 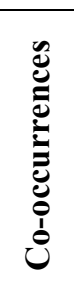 & 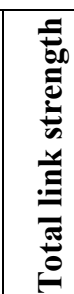 \\
\hline \multirow{17}{*}{1} & \multirow{17}{*}{17} & \multirow{17}{*}{$\begin{array}{l}\text { 苂 } \\
\text { 忢 }\end{array}$} & \multirow{17}{*}{37} & \multirow{17}{*}{ 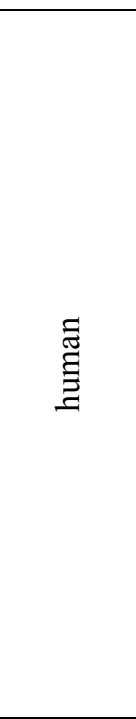 } & \multirow{17}{*}{249} & adult & 13 & 96 \\
\hline & & & & & & complexity & 11 & 27 \\
\hline & & & & & & costs & 19 & 77 \\
\hline & & & & & & female & 13 & 105 \\
\hline & & & & & & human & 37 & 249 \\
\hline & & & & & & interpersonal communication & 24 & 184 \\
\hline & & & & & & leadership & 13 & 80 \\
\hline & & & & & & learning & 12 & 59 \\
\hline & & & & & & male & 13 & 105 \\
\hline & & & & & & organization & 13 & 89 \\
\hline & & & & & & organization and management & 15 & 129 \\
\hline & & & & & & organizational culture & 15 & 84 \\
\hline & & & & & & patient care & 10 & 69 \\
\hline & & & & & & patient safety & 10 & 68 \\
\hline & & & & & & problem solving & 18 & 77 \\
\hline & & & & & & uncertainty & 22 & 82 \\
\hline & & & & & & uncertainty analysis & 20 & 76 \\
\hline \multirow{17}{*}{2} & \multirow{17}{*}{17} & \multirow{17}{*}{ 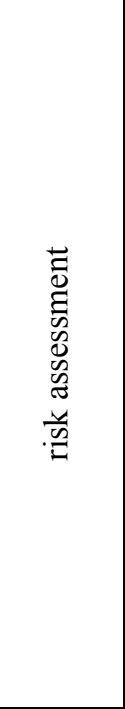 } & \multirow{17}{*}{146} & \multirow{17}{*}{ 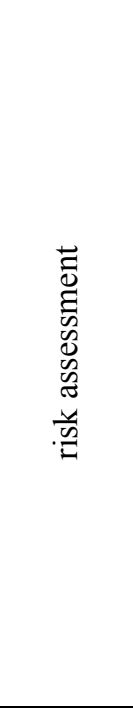 } & \multirow{17}{*}{592} & communication systems & 11 & 47 \\
\hline & & & & & & electronic commerce & 10 & 35 \\
\hline & & & & & & enterprise resource planning & 14 & 52 \\
\hline & & & & & & government data processing & 12 & 52 \\
\hline & & & & & & ict & 15 & 34 \\
\hline & & & & & & information and communication technologies & 39 & 160 \\
\hline & & & & & & information technology & 51 & 217 \\
\hline & & & & & & life cycle & 11 & 47 \\
\hline & & & & & & management science & 25 & 144 \\
\hline & & & & & & planning & 17 & 80 \\
\hline & & & & & & risk analysis & 61 & 284 \\
\hline & & & & & & risk assessment & 146 & 592 \\
\hline & & & & & & security of data & 15 & 67 \\
\hline & & & & & & societies and institutions & 33 & 149 \\
\hline & & & & & & strategic planning & 16 & 75 \\
\hline & & & & & & supply chain management & 42 & 102 \\
\hline & & & & & & supply chains & 21 & 98 \\
\hline
\end{tabular}


Cont. table 1.

\begin{tabular}{|c|c|c|c|c|c|c|c|c|}
\hline \multirow{17}{*}{3} & \multirow{17}{*}{17} & \multirow{17}{*}{ 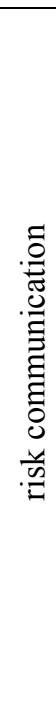 } & \multirow{17}{*}{125} & \multirow{17}{*}{ 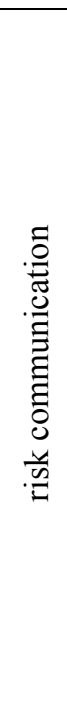 } & \multirow{17}{*}{403} & accident prevention & 21 & 114 \\
\hline & & & & & & accidents & 14 & 62 \\
\hline & & & & & & climate change & 24 & 57 \\
\hline & & & & & & education & 10 & 43 \\
\hline & & & & & & floods & 11 & 49 \\
\hline & & & & & & food safety & 14 & 37 \\
\hline & & & & & & hazards & 19 & 56 \\
\hline & & & & & & health care & 15 & 69 \\
\hline & & & & & & health risks & 28 & 131 \\
\hline & & & & & & innovation & 34 & 127 \\
\hline & & & & & & occupational risks & 12 & 57 \\
\hline & & & & & & perception & 15 & 70 \\
\hline & & & & & & personnel training & 12 & 59 \\
\hline & & & & & & risk communication & 125 & 403 \\
\hline & & & & & & risk perception & 95 & 361 \\
\hline & & & & & & safety & 24 & 109 \\
\hline & & & & & & safety engineering & 20 & 70 \\
\hline \multirow{17}{*}{4} & \multirow{17}{*}{17} & \multirow{17}{*}{ 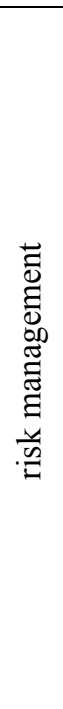 } & \multirow{17}{*}{392} & \multirow{17}{*}{ 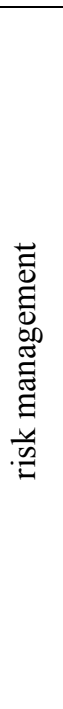 } & \multirow{17}{*}{1446} & communication technologies & 28 & 72 \\
\hline & & & & & & competition & 14 & 59 \\
\hline & & & & & & computer software & 12 & 47 \\
\hline & & & & & & contracts & 15 & 67 \\
\hline & & & & & & economic and social effects & 13 & 65 \\
\hline & & & & & & economics & 26 & 126 \\
\hline & & & & & & industrial management & 25 & 112 \\
\hline & & & & & & information management & 63 & 291 \\
\hline & & & & & & information systems & 35 & 164 \\
\hline & & & & & & laws and legislation & 15 & 60 \\
\hline & & & & & & managers & 20 & 96 \\
\hline & & & & & & marketing & 14 & 53 \\
\hline & & & & & & outsourcing & 22 & 48 \\
\hline & & & & & & product development & 11 & 32 \\
\hline & & & & & & risk management & 392 & 1446 \\
\hline & & & & & & sustainable development & 29 & 132 \\
\hline & & & & & & technology & 25 & 96 \\
\hline \multirow{14}{*}{5} & \multirow{14}{*}{14} & \multirow{14}{*}{ 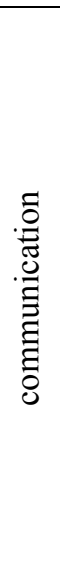 } & \multirow{14}{*}{162} & \multirow{14}{*}{ 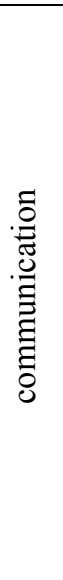 } & \multirow{14}{*}{604} & communication & 162 & 604 \\
\hline & & & & & & content analysis & 13 & 47 \\
\hline & & & & & & corporate communications & 12 & 18 \\
\hline & & & & & & corporate governance & 27 & 37 \\
\hline & & & & & & corporate social responsibility & 40 & 37 \\
\hline & & & & & & public policy & 12 & 54 \\
\hline & & & & & & public relations & 16 & 67 \\
\hline & & & & & & reputation & 13 & 22 \\
\hline & & & & & & risk & 65 & 242 \\
\hline & & & & & & social aspects & 19 & 80 \\
\hline & & & & & & stakeholder & 18 & 66 \\
\hline & & & & & & stakeholders & 22 & 65 \\
\hline & & & & & & transparency & 10 & 28 \\
\hline & & & & & & trust & 40 & 119 \\
\hline
\end{tabular}


Cont. table 1 .

\begin{tabular}{|c|c|c|c|c|c|c|c|c|}
\hline \multirow{14}{*}{6} & \multirow{14}{*}{14} & \multirow{14}{*}{ 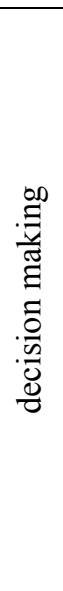 } & \multirow{14}{*}{89} & \multirow{14}{*}{ 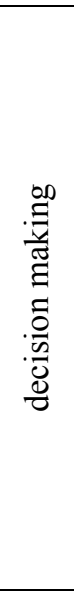 } & \multirow{14}{*}{411} & artificial intelligence & 12 & 61 \\
\hline & & & & & & behavioural research & 17 & 95 \\
\hline & & & & & & civil defence & 26 & 165 \\
\hline & & & & & & crisis communication & 27 & 68 \\
\hline & & & & & & crisis management & 36 & 106 \\
\hline & & & & & & decision making & 89 & 411 \\
\hline & & & & & & decision making process & 11 & 60 \\
\hline & & & & & & decision support systems & 12 & 66 \\
\hline & & & & & & disasters & 54 & 270 \\
\hline & & & & & & emergency management & 26 & 138 \\
\hline & & & & & & emergency services & 10 & 51 \\
\hline & & & & & & internet & 18 & 48 \\
\hline & & & & & & social media & 23 & 72 \\
\hline & & & & & & social networking (online) & 16 & 100 \\
\hline \multirow{13}{*}{7} & \multirow{13}{*}{13} & \multirow{13}{*}{ 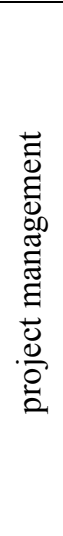 } & \multirow{13}{*}{119} & \multirow{13}{*}{ 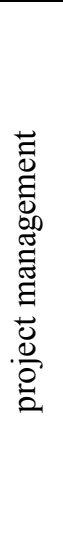 } & \multirow{13}{*}{436} & collaboration & 15 & 38 \\
\hline & & & & & & construction industry & 47 & 237 \\
\hline & & & & & & construction projects & 23 & 101 \\
\hline & & & & & & critical success factors & 11 & 43 \\
\hline & & & & & & enterprise risk management & 10 & 42 \\
\hline & & & & & & factor analysis & 10 & 52 \\
\hline & & & & & & human resource management & 33 & 148 \\
\hline & & & & & & knowledge based systems & 10 & 58 \\
\hline & & & & & & knowledge management & 37 & 154 \\
\hline & & & & & & project management & 119 & 436 \\
\hline & & & & & & quality control & 12 & 60 \\
\hline & & & & & & risk identification & 11 & 61 \\
\hline & & & & & & structural equation modeling & 12 & 53 \\
\hline
\end{tabular}

Source: own processing via VOSviewer software, data extracted from Scopus database. 